\title{
Effect of Induced Fatigue of Unaffected Limb on Balance in Children with Hemiplegia
}

\author{
MARWA M. NAGEEB, M.Sc.; FATEN H. ABD EL-AZEIM, Ph.D. and SHOROUK EL-SHENNAWY, Ph.D. \\ The Department of Pediatric Physical Therapy, Faculty of Physical Therapy, Cairo University
}

\begin{abstract}
Background: Children with hemiplegic cerebral palsy bearing weight mostly through the unaffected leg and may be a strategy to compensate for muscle paresis in the hemiplegic leg causing fatigue of unaffected limb and impaired balance.

Aim: To determine the immediate effect of induced fatigue of unaffected limb on balance in children with hemiplegic cerebral palsy.

Patients and Methods: 29 children with hemiplegic cerebral palsy ( $8.9 \pm 2.3$ years). Before and after induced fatigue of unaffected limb the balance were recorded by Biodex balance system.

Results: There were significant difference before and after fatigue in balance overall stability index $(p<0.001)$, antroposterior stability index $(p=0.003)$, mediolatral stability index $(p=0.002)$.

Conclusion: Fatigue of unaffected limb deteriorates balance in children with hemiplegia.
\end{abstract}

Key Words: Fatigue - Balance - Hemiplegic cerebral palsy.

\section{Introduction}

CEREBRAL Palsy (CP) describes a group of disorders of posture and movement that occur as a result of a non-progressive disturbance in the developing fetal or infant brain [1]

Impaired postural control in children with $\mathrm{CP}$ has been shown to result from multiple factors: Musculoskeletal problems, including contractures, reduced range of motion, and shifts in initial alignment, all affect reactive balance control in children with CP [2].

Children with hemiplegia about $33 \%$ of children with cerebral palsy which is characterized by one side brain affection that causes weakness and

Correspondence to: Dr. Marwa M. Nageeb, The Department of Pediatric Physical Therapy, Faculty of Physical Therapy, Cairo University spasticity contralateral to the affected brain hemisphere [3]

Children with unilateral CP tend to have impaired coordination of movement, reduced betweenlimb synchronization, and less weight bearing on the affected side, which in turn can affect the ability to maintain an upright weight-bearing position as well as gait [4]

Balance defined as the act of maintaining, achieving, or restoring the center of mass relative to the base of support [5]. The maturation of balance skills in children with cerebral palsy is also known to be delayed or diminished when compared to typically developing children [6]. Due to the musculoskeletal asymmetry in children with hemiplegic $\mathrm{CP}$, all balance parameters show significant differences when compared with those of typically developing children [7].

Fatigue can be defined as the inability to maintain a power output during or following a repeated muscular contraction [8]. Muscle fatigue can influence the various mechanisms that regulate balance. Studies in young people show that muscle fatigue in the lower limbs increases postural sway [9], so this study concerned about the effect of unaffected limb fatigue on balance in hemiplegic children.

\section{Patients and Methods}

This study was designed to investigate the effect of unaffected limb fatigue on balance. This study was conducted in the laboratory of isokinetic dynamometer from April 2017 to December 2017 at the Faculty of Physical Therapy, Cairo University. Twenty nine children with hemiplegic cerebral palsy were recruited from Mataria Hospital, Embaba Hospital, Abu Al-Resh Hospital and Banha Hospital. Data were collected at the outpatient Clinic of the Faculty of Physical Therapy, Cairo 
University. The study was approved by the Ethics Committee of Faculty of Physical Therapy, Cairo University, and all parents have signed written consent forms at the beginning of the study.

\section{Patients:}

Twenty nine children with hemiplegic CP (6$14 \mathrm{yrs})$, were recruited from the outpatient clinic of the Faculty of Physical Therapy, Cairo University.

Inclusion criteria: Their gross motor ability was I/II according to GMFCS; spasticity was I/I + according to Modified Ashworth Scale.

Exclusion criteria: Children were excluded if they had any orthopedic surgery or botulinum toxin injections within 12 months and 6 months respectively, prior to the start of study.

\section{Material:}

\section{Biodex balance system:}

Biodex balance system (Biodex Crop. Shirley, NY) was used to assess the balance. It is a multiaxial tilting platform which allows objective evaluation of the ability of a participant to control single and double-limb postural stance on an unstable platform. It assess overall postural stability, anterior/posterior and medial/lateral stability. High score is indicative poor balance [10]. Each participant was asked to stand bear feet on the balance platform, with eyes open, and to remain as stable as possible. Video screen in front of patient for visual feedback, and the individuals attempt to keep the dot at the center of the plot. All participants were tested on stability level 7 according to a prior pilot study. Each measurement lasted for 20 seconds [11]

\section{Isokinetic dynamometer:}

Fatigue of unaffected limb was induced using Biodex system 3 Pro Isokinetic dynamometer (Biodex Medical INC., Shirely, New York, USA). The subject sat in the Biodex chair in semi reclining position with the angle of the hip at 70 degrees. Fatigue protocol was applied at repetitions of $35^{\circ}$ reciprocal maximal concentric contractions of knee flexion and extension, with a range of motion of $90^{\circ}$ at an angular velocity of $60^{\circ} / \mathrm{s}$ [12]

\section{Results}

Twenty nine hemiplegic children of both sexes ( 20 boys and 9 girls) participated in this study with their mean \pm SD of ages, weights, heights and BMI were $8.9 \pm 2.3$ years, $26.4 \pm 7.8 \mathrm{~kg}, 123.3 \pm 9.1 \mathrm{~cm}$ and $17.1 \pm 2.9 \mathrm{~kg} / \mathrm{m}^{2}$ respectively. The demographic data of the participants is shown in (Table 1).

As shown in (Table 2), there was significant difference in postural balance between pre and post-fatigue in over all, anterioposterior and mediolatral stability index $(p<0.001, p=0.003$ and $p=$ 0.002 ) respectively.

Table (1): Demographic data of the participants.

\begin{tabular}{llllcc}
\hline & Mean & SD & Median & Minimum & Maximum \\
\hline Age $(\mathrm{yrs})$. & 8.9 & 2.3 & 9 & 6 & 14 \\
Weight $(\mathrm{kg})$ & 26.4 & 7.8 & 25 & 16 & 50 \\
Height $(\mathrm{cm})$ & 123.3 & 9.1 & 121 & 113 & 153 \\
BMI $\left(\mathrm{kg} / \mathrm{m}^{2}\right)$ & 17.1 & 2.9 & 17.23 & 11.3 & 24.85 \\
\hline
\end{tabular}

BMI: Body Mass Index.

Table (2): Biodex scoring before and after fatigue.

\begin{tabular}{|c|c|c|c|c|c|c|c|c|c|}
\hline & \multicolumn{2}{|c|}{ Before } & \multicolumn{2}{|c|}{ After } & \multirow{2}{*}{$\begin{array}{c}\text { Mean } \\
\text { difference }\end{array}$} & \multicolumn{2}{|c|}{$95 \% \mathrm{CI}$} & \multicolumn{2}{|c|}{ Percent } \\
\hline & Mean & SD & Mean & SD & & Lower & Upper & Change & $p$-value \\
\hline Over all stability index & 2 & 0.6 & 2.5 & 0.8 & 0.5 & 0.3 & 0.7 & 24.8 & $<0.001$ \\
\hline AP stability index & 1.3 & 0.4 & 1.7 & 0.7 & 0.4 & 0.1 & 0.6 & 28.9 & 0.003 \\
\hline ML stability index & 1.5 & 0.6 & 1.9 & 0.7 & 0.4 & 0.1 & 0.6 & 23.9 & 0.002 \\
\hline
\end{tabular}

SD: Standard Deviation

\section{Discussion}

The present study investigates the effect of induced fatigue of unaffected limb on balance in children with hemiplegic cerebral palsy. The results showed that fatigue caused deterioration of balance in both frontal and sagittal planes.

Balance performance impaired due to golgi tendon desensitization and muscle spindle desensitization or ligament relaxation occurs with fatigue
[13]. Simoneau et al., [14] examined how moderate fatigue by fast walking affected the control of balance they reported an initial negative impact on the control of balance. In addition, Miura et al., [15] and Lee et al., [16] found that the muscular fatigue induces an adverse change in the proprioception as well as postural control. Yaggie and McGregor [17] also examined the impact of lower extremity fatigue on balance indexes using the Sport-KAT-2000 system before and immediately 
after the fatigue protocol. They reported that lower extremity fatigue adversely affected balance index scores, which is in agreement with the results of our current study.

Common observation is that cycling exercise, performed under intensive or prolonged modes, impairs the ability to maintain standing balance that is also confirmed my study $[\mathbf{1 8 , 1 9 ]}$

Nardone et al., [20], reported that changes in the sensory proprioceptive information and their integration and decrease of the muscular system efficiency due to muscular fatigue.

Cycling exercising to fatigue, defined as a decreased force generating capacity, has been shown to reduce knee joint proprioception which is one of sensory system of balance [21]. Fatigue following various types of exercises has been found to alter balance and postural stability [22]

\section{Conclusion:}

It's concluded that fatigue of the unaffected limb in children with hemiplegic cerebral palsy impaired balance because hemiplegic children mostly depend on the unaffected limb to maintain their balance.

\section{References}

1- PALISANO, ROBERT J., STEVEN E. HANNA, PETER L. ROSENBAUM, and BETH TIEMAN: "Probability of Walking, Wheeled Mobility, and Assisted Mobility in Children and Adolescents with Cerebral Palsy." Developmental Medicine and Child Neurology, 52 (1): 66-71, 2010.

2- SANKAR, CHITRA and NANDINI MUNDKUR: "Cerebral Palsy-Definition, Classification, Etiology and Early Diagnosis." The Indian Journal of Pediatrics, 72 (10): 865-68, 2005

3- CIMOLIN, VERONICA, MANUELA GALLI, NUNZIO TENORE, GIORGIO ALBERTINI and M. CRIVELLINI: "Gait Strategy of Uninvolved Limb in Children with Spastic Hemiplegia.” Europa Medicophysica, 43 (3): 30310, 2007.

4- BAX, MARTIN, et al.: "Proposed Definition and Classification of Cerebral Palsy, April 2005." Developmental Medicine \& Child Neurology, 47 (8): 571-76, 2005.

5- MANCINI M. and F.B. HORAK: "The Relevance of Clinical Balance Assessment Tools to Differentiate Balance Deficits." European Journal of Physical and Rehabilitation Medicine, 46 (2): 239-48, 2010.

6- EYRE J.A.: "Corticospinal Tract Development and Its Plasticity after Perinatal Injury." Neuroscience and Biobehavioral Reviews, 31 (8): 1136-49, 2007.

7- SAYGI E.K., O. OZKOK and G. AKYUZ: "Evaluation of Postural Stability in Children with Hemiplegic Cerebral Palsy." Turkiye Fiziksel Tip ve Rehabilitasyon Dergisi 57: 229, 2011.
8- MOREAU, NOELLE, LI LI and DIANE L. DAMIANO "A Feasible and Reliable Muscle Fatigue Assessment Protocol for Individuals with Cerebral Palsy." Pediatric Physical Therapy, 20 (1): 59-65, 2008.

9- VITIELLO, DAMIEN, et al.: "Walking-Induced Muscle Fatigue Impairs Postural Control in Adolescents with Unilateral Spastic Cerebral Palsy." Research in Developmental Disabilities, 53-54: 11-8, 2016.

10 - TESTERMAN, CHRIS and ROBERT VANDER GRIEND: "Evaluation of Ankle Instability Using the Biodex Stability System." Foot and Ankle International, 20 (5): 3 17-21, 1999.

11- CLE ORIGINA and L. ARTI: "Evaluation of Dynamic Postural Balance Using the Biodex Stability System in Rheumatoid Arthritis Patients", 462-67, 2006.

12- EKEN M.M., A.J. DALLMEIJER, H. HOUDIJK and C. A.M. DOORENBOSCH: "Muscle Fatigue during Repetitive Voluntary Contractions: A Comparison between Children with Cerebral Palsy, Typically Developing Children and Young Healthy Adults." Gait \& Posture, 38 (4): 962-67, 2013

13- CHANGELA, PURVI K. and K. SELVAMANI: "A Study to Evaluate the Effect of Fatigue on Knee Joint Proprioception and Balance in Healthy Individuals." Romanian Sports Medicine Society VIII (2): 1851-57, 2012.

14- SIMONEAU, MARTIN, FRANÇOIS BÉGIN and NORMAND TEASDALE: "The Effects of Moderate Fatigue on Dynamic Balance Control and Attentional Demands." Journal of Neuroengineering and Rehabilitation, 3: 22, 2006.

15- MIURA KAZUTOMO, et al.: "The Effect of Local and General Fatigue on Knee Proprioception." Arthroscopy -Journal of Arthroscopic and Related Surgery, 20 (4): 414-8, 2004.

16- LEE, HUNG MAAN, JIANN JONG LIAU, CHENG KUNG CHENG, CHUAN MING TAN and JUI TIEN SHIH: "Evaluation of Shoulder Proprioception Following Muscle Fatigue." Clinical Biomechanics, 18 (9): 843-47, 2003.

17- YAGGIE, JAMES A. and STEPHEN J. McGREGOR: "Effects of Isokinetic Ankle Fatigue on the Maintenance of Balance and Postural Limits." Archives of Physical Medicine and Rehabilitation, 83 (2): 224-8, 2002.

18- GAUCHARD, GÉROME C., PIERRE GANGLOFF, ALEXANDRE VOURIOT, JEAN PIERRE MALLIÉ and PHILIPPE P. PERRIN: "Effects of Exercise-Induced Fatigue with and without Hydration on Static Postural Control in Adult Human Subjects.” International Journal of Neuroscience, 112 (10): 1191-206, 2002.

19- LEPERS, ROMUALD, ANDRÉ X. BIGARD, JEANPIERRE DIARD, JEAN-FRANCOIS GOUTEYRON and CHARLES Y. GUEZENNEC: "Posture Control after Prolonged Exercise." European Journal of Applied Physiology, 76 (1): 55-61, 1997.

20- NARDONE, ANTONIO, JESSICA TARANTOLA, ANDREA GIORDANO and MARCO SCHIEPPATI: "Fatigue Effects on Body Balance.” Electroencephalography and Clinical Neurophysiology-Electromyography and Motor Control, 105 (4): 309-20, 2002 
21- ROBERTS, DAVID, EVA AGEBERG, GERT ANDERSSON and THOMAS FRIDÉN: "Effects of Short-Term Cycling on Knee Joint Proprioception in Healthy Young Persons." The American Journal of Sports Medicine, 31 (6): 990-4, 2003.
22- JOHNSTON R.B., M.E. HOWARD, P.W. CAWLEY and G.M. LOSSE: "Effect of Lower Extremity Muscular Fatigue on Motor Control Performance." Medicine and Science in Sports and Exercise, 30 (12): 1703-7, 1998.

\title{
تآثير الإجهاد المستحس للطرف الغير مصاب على الإتزان فى آطفال الفالج الشقى الفيرم
}

\author{
المقدمة:عادة آطفال الفلج الثقى يحملمن معظم وذنهم على الطرف الغير مصاب لتعويض ضعف العضلات في الطرف المصاب مما ينتج \\ عنه إجهاد الجزء السليم، والتآثير على الإتزان. \\ الهدف: لمعرفة تآثير إجهاد الطرف الغير مصاب على الإتزان في آطفال الفالج الثقى.

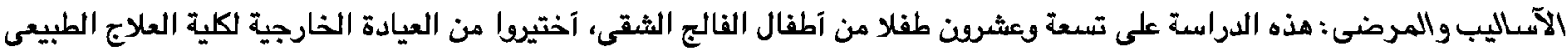

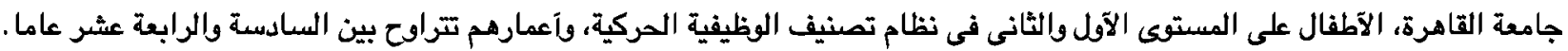 \\ النتائج: آظهرت النتائج وجود دلالة إحصائية إيجابية من تآتير إجهاد الطرف الغير مصاب على الإتزان في آطفال الفالج الثقى. \\ الخلاصة: إجهاد الطرف الغير مصاب فى حالات آطفال الفالج الثقى يؤثر على الإتزان.
}

